\title{
Commonality in ask-side vs. bid-side liquidity
}

\author{
Ahmet Sensoy \\ Faculty of Business Administration, Bilkent University, Ankara, 06800, Turkey
}

\section{A R T I C L E I N F O}

\section{Keywords:}

Market microstructure

Commonality in liquidity

Order book

Ask-side liquidity

Bid-side liquidity

JEL classification:

D23

D82

G12

G14

G23

\begin{abstract}
A B S T R A C T
We decompose the cost of trading into buy-side and sell-side using the limit order book. By using various position sizes to trade, we look for commonality in liquidity on different sides and also at the different levels of the order book. We find that bid-side liquidity has a higher commonality than ask-side liquidity for small position sizes to trade. On the other hand, ask-side commonality becomes stronger once position size exceeds a certain level. Empirical evidence suggests that this switching pattern may be due to the investors' over-reaction to a positive and under-reaction to a negative market trend.
\end{abstract}

\section{Introduction}

Starting with the works of Chordia et al. (2000), Huberman and Halka (2001) and Hasbrouck and Seppi (2001), we have been presented an extensive body of research that examines the co-movement between individual stock liquidity and market-wide liquidity. Accordingly, liquidity is subject to a spillover effect that influences other firms traded in the same stock exchange. Thus, liquidity is not just the trading cost of an individual stock but also a potential systemic risk factor due to commonality (Pastor and Stambaugh, 2003; Acharya and Pedersen, 2005; Sadka, 2006; Bekaert et al., 2007; Korajczyk and Sadka, 2008; Kamara et al., 2008). In that sense, understanding the commonality phenomenon is important as it might help us to design new financial stabilization policies, or provide more accurate guidance for portfolio selections.

Although the literature is exhaustive on liquidity and it's determinants, little research has been conducted on the different sides of liquidity; i.e., ask-side vs. bid-side. ${ }^{1}$ In fact, to the best of our knowledge, no study has focused on the commonality in different sides of the liquidity. This fact might not be surprising since many studies on commonality has focused on the US market, where there used to be a dealership system with dedicated market makers that have a binding obligation to supply liquidity for both ask and bid side which would create a symmetric liquidity effect. ${ }^{2}$ However, in modern financial markets, where most of them work with a fully orderdriven structure, traders have no compelling reason to be simultaneously active on both sides of the market. On the contrary, many traders have different liquidity needs, asset valuations, and risk aversion, and they place orders on different sides of the book. It is very plausible to assume that buy and sell sides of the order book are explained by different factors. Therefore, we focus on the

\footnotetext{
E-mail addresses: ahmet.sensoy@bilkent.edu.tr, ahmets@fen.bilkent.edu.tr.

${ }^{1}$ The importance of the asymmetry between different sides of liquidity has been emphasized in the study of Brennan et al. (2012). By using proxies for trading costs in both sides, authors show that ask-side liquidity is priced more strongly than bid-side liquidity, and their results hold even after controlling for several known determinants.

${ }^{2}$ The inventory model of Stoll (1978) in microstructure literature implies symmetrical ask and bid side variations as the dealer shifts bid and ask quotations simultaneously for inventory management.
} 
commonality in different sides of liquidity in this study to fill a big gap in the literature.

To differentiate between the ask- and bid-side liquidity, we use a measure different from the common ones used in the literature. In particular, by using full order flow data of each stock in Borsa Istanbul (Turkish stock market), we construct a special weighted spread that measures the cost of buying and selling for a given amount of position. By using different positions to trade, we look for commonality in liquidity on different sides and also at the different levels of the order book.

Building upon the existing literature, we apply the approaches of Chordia et al. (2000) and Chung and Chuwonganant (2014) to measure commonality. Our results verify that commonality exists in Borsa Istanbul at different levels of the order book for both ask- and bid-side, even after controlling for several determinants of liquidity. However, the commonality is not symmetric for bid and ask-sides, which is probably due to the fact that market is consisting of heterogeneous traders with different trading strategies, trading needs, and asset valuations, and limit order book system allows this heterogeneity to be reflected on the commonality in liquidity. Interestingly, bid-side has a higher commonality than ask-side for small position sizes to trade. On the other hand, ask-side commonality becomes stronger once position size exceeds a certain level. Empirical evidence suggests that this switching pattern may be due to the investors' over-reaction to a positive market trend and under-reaction to a negative market trend. Accordingly, trading strategies intended to reduce transaction costs should depend on market momentum, intended trade direction and the desired order amount to be traded.

In the rest of this work, we introduce our liquidity measure and explain our sample selection in Section 2. Section 3 contains the empirical work. Finally, Section 4 concludes.

\section{Exchange liquidity measure (XLM) and sample selection}

The idea is to construct a methodology which would measure the cost of buying and selling for a given position size $Q$ (money) at a specific time $t$. Consider the snapshot of the order book of a stock at time $t$. Let $a_{i}$ and $b_{i}$ be the $i^{\text {th }}$ best ask and bid prices respectively at that instant. Denote by $P_{\text {mid }} \equiv\left(a_{1}+b_{1}\right) / 2$ the mid price of $a_{1}$ and $b_{1}$ (so called fair price); $L P \equiv\left(a_{1}-b_{1}\right) / 2 P_{\text {mid }}$ the half of the bid-ask spread (so-called liquidity premium); $b(n)=\left(\sum b_{i} n_{i}\right) / n$ where $\sum n_{i}=n$, the weighted average bid-price at which the total of $n$ shares can be sold; $a(n)=\left(\sum a_{i} n_{i}\right) / n$ where $\sum n_{i}=n$, the weighted average ask-price; $A P M_{b i d}(Q) \equiv(b(1)-b(n)) / P_{\text {mid }}$, where $P_{\text {mid }} \times n=Q$ the size of the position in TL, called the adverse price movement for the bid-side; similarly $A P M_{\text {ask }}(Q) \equiv(a(1)-a(n)) / P_{\text {mid }}$, called the adverse price movement for the ask-side. Then, the liquidity measures are calculated as the following;

$$
\begin{aligned}
& X L M_{A}(Q)=100 \times\left(L P+A P M_{\text {ask }}(Q)\right) \\
& X L M_{B}(Q)=100 \times\left(L P+A P M_{b i d}(Q)\right)
\end{aligned}
$$

where $X L M_{A}(Q)\left(X L M_{B}(Q)\right)$ is the execution cost for ask (bid) side. ${ }^{3}$

Our sample comes from Borsa Istanbul database and covers 4 years of intra-day data from January 4, 2010 to December $31,2013$. The main requirement of the $X L M$ methodology is that a stock should be traded via continuous auction since the ask price must always be higher than the bid price. Therefore, we remove the stocks traded via single price auction. We also do not want to be affected by any initial public offering or delisting effect so we focus on the stocks that are listed on the stock exchange during the whole sample period. During the continuous trading period on each day, we take six snapshots of the order book of each stock at 10:00, 11:00, 12:00, 15:00, 16:00 and 17:00, and calculate the $X L M_{A}$ and $X L M_{B}$ for five different position sizes of $Q=1000,10,000$, $25,000,50,000,100,000$ TL. ${ }^{4}$ The last criterion to be introduced is based on the position availability as it is not always possible to find a hypothetical order of size $Q$, in particular when $Q$ is large. Accordingly, we remove the stocks if the order book does not carry the required positions more than $2 \%$ of the whole sample period. This criterion leaves us 133 (out of 369) stocks to analyze. Finally, the daily liquidity measure is constructed by taking the arithmetic mean of the six intra-day values. ${ }^{5}$

Through the rest of this study, we denote $X L M_{A}$ and $X L M_{B}$ by $A$ and $B$ to simplify notations, and we will use $Q 1, Q 2, Q 3, Q 4, Q 5$ to denote the position sizes $Q=1000,10,000,25,000,50,000,100,000$ TL respectively. For example, $Q 1 A$ and $Q 4 B$ would mean $X L M_{A}(1000 T L)$ and $X L M_{B}(50,000 T L)$.

\section{The model and the results}

We start with the market model of Chordia et al. (2000) to examine the commonality in liquidity in the order book,

$$
D L_{i, t}=\beta_{i 0}+\beta_{i 1} D L_{M, t}+\beta_{i 2} D L_{M, t-1}+\beta_{i 3} D L_{M, t+1}+\beta_{i 4} R_{M, t}+\beta_{i 5} R_{M, t-1}+\beta_{i 6} R_{M, t+1}+\beta_{i 7} D V_{i, t}+\varepsilon_{i, t}
$$

where $L_{i, t}$ is a general notation to denote the measure of an individual liquidity for stock $i$ on day $t$; $L_{M, t}$ is equally-weighted cross sectional average of the liquidity variable for all stocks on day $t$ excluding stock $i ; R_{M, t}$ is equally-weighted cross sectional average of the returns (daily percentage changes) for all stocks on day $t$ excluding stock $i$; and $V_{i, t} \equiv \frac{\left(P_{i, t}^{H}-P_{i, t}^{L}\right)}{\left(P_{i, t}^{H}+P_{i, t}^{L}\right) / 2}$ is a proxy for the individual

\footnotetext{
${ }^{3}$ The same measure was previously used by Domowitz et al. (2005) and Rosch and Kaserer (2014) in the context of liquidity commonality. However, these studies focus on the cost of roundtrip instead of differentiating between ask- and bid-side.

${ }^{4}$ These position sizes roughly correspond to $50 \%, \% 75, \% 90, \% 95$ and $\% 99$ percentile of the single order sizes in the sample period.

5 The same dataset was used by Sensoy (2016) to measure the impact of monetary policy and macroeconomic announcements on commonality in liquidity; and by Sensoy (2017) to analyze the firm size and ownership structure on systematic liquidity risk.
} 
volatility of stock $i$ on day $t$, with $P_{i, t}^{H}$ and $P_{i, t}^{L}$ denoting the highest and lowest prices respectively. The operator $D$ stands for the daily percentage change wherever it is used. Exclusion of the individual stock variables in constructing the aggregate variables is to remove the effect of stock $i$ 's own variation on the market average and remove the constraint that the cross-sectional average of the betas has to be unity. The additional lead and lag of the changes in the market average liquidity are used to capture the effect of non-concurrent adjustments in the liquidity variation at stock and market level. The (concurrent, lagged and lead) market return is added to remove spurious dependence induced by an association between returns and spread measures. The change in individual volatility is included as it might be an important variable influencing liquidity. Finally, unless otherwise stated, all linear estimations are performed by Newey-West regressions.

We first estimate the time-series model in Eq. (1) for each stock, and then report the cross-sectional mean of the estimated beta coefficients in Panel A of Table $1 .^{6}$ The results reveal a clear evidence of co-movement in the order book liquidity for both ask- and bid-side. We observe a strong contemporaneous commonality as average $\beta_{1}$ values range from 0.77 to 0.90 for the ask-side, and from 0.77 to 0.92 for the bid-side with all $t$-statistics greater than 20. $\beta_{2}$ (lagged beta) means are usually small and insignificant compared with the $\beta_{1}$ (contemporaneous beta) averages. However, $\beta_{3}$ (lead beta) averages produce significant negative, albeit, little values in magnitude.

Considering concurrent betas $\left(\beta_{1}\right)$, more than $99 \%$ of our sample stocks have positive individual beta estimates and at least $85 \%$ of them are positively significant at the $95 \%$ confidence level for any given position size to trade. Moreover, there is no negative significant individual $\beta_{1}$ value. The percentage of stocks with positive and negative significant lagged (lead) betas are less than $9 \%$ and $13 \%(7 \%$ and $15 \%)$ respectively.

Although we adjust the $t$-statistics for the mean concurrent $\left(\beta_{1}\right)$, lagged $\left(\beta_{2}\right)$ and lead $\left(\beta_{3}\right)$ betas; we can not perform a similar procedure for the sum of the mean beta coefficients $\left(\beta_{1}+\beta_{2}+\beta_{3}\right)$ since the market model regression in Eq. (1) does not provide its variance estimate. Therefore, to check whether this sum is also significant, we follow the procedure suggested by Chordia et al. (2000). We sort the sample stocks alphabetically and run 132 time series regressions between adjacent residuals; i.e.,

$$
\varepsilon_{j+1, t}=\gamma_{j, 0}+\gamma_{j, 1} \varepsilon_{j, t}+\zeta_{j, t} \quad(j=1, \ldots, 132),
$$

where $\gamma_{j, 0}$ and $\gamma_{j, 1}$ are coefficients to be estimated. The $t$-statistics for $\gamma_{j, 1}$ is expected to provide evidence about cross-equation dependence. Panel C of Table 1 displays the sample characteristics for the $t$-statistics of $\gamma_{j, 1}$ and also presents the average correlations between $\varepsilon_{j+1, t}$ and $\varepsilon_{j, t}$. Accordingly, there is little evidence of cross-equation dependence in our sample. For all position sizes to trade, the proportion of significant $t$-values are less than $10 \%$, with mean and median $t$-statistics being confined to the interval [ -0.17 , 0.08]. Plus, near zero average correlations (positive and less than 0.01 in any case) imply that adjusting for cross-equation dependence would not have a significant impact on the qualitative conclusions.

Taking mean $\beta_{1}+\beta_{2}+\beta_{3}$ as the main measure of commonality, we notice that when we walk up through the order book, commonality in cost of trading has a tendency to decrease with the increasing position size to trade for both sides (see Fig. 1). For relatively small trading positions, commonality in bid-side is stronger than the commonality in ask-side. However, as the position size to trade exceeds a certain amount, the commonality on the ask-side becomes stronger than the commonality on the bid-side.

\subsection{Robustness check: commonality vs. industry affiliation and individual determinants}

Previous literature states that industry affiliation (Brockman and Chung, 2002; Brockman et al., 2009; Chung and Chuwonganant, 2014) as well as individual properties like volatility, trading volume and price have significant effects on a share's own liquidity (Benston and Hagerman, 1974; Stoll, 1978; 2000). Therefore, we estimate the following regression model given in Eq. (2) for each stock using daily time series to examine the commonality while controlling for industry affiliation and main individual liquidity determinants.

$$
\begin{aligned}
\log \left(L_{i, t}\right)= & \alpha_{i 0}+\alpha_{i 1} \log \left(L_{M, t}\right)+\alpha_{i 2} \log \left(L_{M, t-1}\right)+\alpha_{i 3} \log \left(L_{M, t+1}\right) \\
& +\alpha_{i 4} \log \left(L_{I, t}\right)+\alpha_{i 5} \log \left(L_{I, t-1}\right)+\alpha_{i 6} \log \left(L_{I, t+1}\right) \\
& +\alpha_{i 7} \log \left(V_{i, t}\right)+\alpha_{i 8} \log \left(V_{i, t-1}\right)+\alpha_{i 9} \log \left(V_{i, t+1}\right) \\
& +\alpha_{i 10} \log \left(P_{i, t}^{w}\right)+\alpha_{i 11} \log \left(V_{0 o} l_{i, t}\right) \\
& +\alpha_{i 12} R_{M, t}+\alpha_{i 13} R_{M, t-1}+\alpha_{i 14} R_{M, t+1}+\varepsilon_{i, t}
\end{aligned}
$$

where the additional regressor $L_{I}$ is an industry-specific average liquidity measure. As with market liquidity, firm $i$ was excluded when computing the industry average. The additional variables $P_{i, t}^{w}$ and $V_{o l} l_{i}$ respectively denote the time-weighted price and TL trading volume of stock $i$ on day $t$. This time, in the spirit of Chung and Chuwonganant (2014), we proceed with a level regression, thus each

\footnotetext{
${ }^{6}$ The $t$-statistics associated with the mean coefficients in Panel A of Table 1 and Table 2 have been adjusted for cross-equation correlations as suggested by Hameed et al. (2010). In particular, the variance of each estimated market liquidity $\beta_{i}$ is obtained from stock $i$ 's market model liquidity commonality regression in Eq. (1). The empirical correlation between the regression residuals for stocks $i$ and $j$ is used to estimate the pairwise correlation between the coefficients $\beta_{i}$ and $\beta_{j}$. Hence, the standard error of the mean estimated coefficient is provided by:
}

$$
\operatorname{StdDev}(\bar{\beta})=\operatorname{StdDev}\left(\frac{1}{N} \sum_{i=1}^{N} \beta_{i}\right)=\frac{1}{N} \sqrt{\sum_{i=1}^{N} \operatorname{Var}\left(\beta_{i}\right)+\sum_{i=1}^{N} \sum_{j=1, j \neq i}^{N} \rho_{i j} \sqrt{\operatorname{Var}\left(\beta_{i}\right) \operatorname{Var}\left(\beta_{j}\right)}}
$$


estimated coefficient represents percent change in the liquidity measures given a $1 \%$ change (i.e., elasticity) in each independent variable. Panel A of Table 2 displays the separate marginal influences of individual attributes on liquidity and compares their magnitude with commonality, measured by market- and industry-wide liquidity in this case ( $t$-statistics are corrected for first-order auto-correlation).

As expected, individual volatility has a positive and highly significant influence on cost of trading. In particular the mean impact of concurrent $\left(\alpha_{7}\right)$, lagged $\left(\alpha_{8}\right)$ and lead $\left(\alpha_{9}\right)$ individual volatility are all significant with the concurrent effect taking the largest values. Moreover, as reported by Panel B of Table 2, percentage of the positive significant individual volatility terms are considerably high with more than $70 \%$ for the concurrent, and 30\% for the lag and lead values (and reaching up to more than $90 \%$ as we go deep in the order book). Significant lag and lead volatility effects indicate that traders take historical uncertainty into account in adjusting their liquidity positions and also make anticipatory adjustments.

As also expected, trading volume $\left(\alpha_{11}\right)$ has a negative and highly significant impact on cost of trading. Similar to the case of volatility; trading activity has a small effect on liquidity in magnitude for small positions, however it increases strikingly as the position size increases, even exceeding the market-wide commonality level at the largest position size Q5 to trade.

Regarding market-wide commonality, we obtain similar findings with the previous sub-section; i.e., market-wide commonality in both bid- and ask-side retains a strong influence on individual stock liquidity even after accounting for several factors. Also, it's impact $\left(\alpha_{1}+\alpha_{2}+\alpha_{3}\right)$ has a decreasing trend for both sides as position size to trade increases.

The findings on industry-wide commonality show that when many factors are taken into account, the significance of industry affiliation is almost none. Results suggest that liquidity does not carry a industry-specific risk or is not exposed to a industry-wide

Table 1

PANEL A: Cross-sectional averages of time series slope coefficients are reported with t-statistics below

\begin{tabular}{|c|c|c|c|c|c|c|c|c|c|}
\hline & & $\beta_{1}$ & $\beta_{2}$ & $\beta_{3}$ & $\beta_{1}+\beta_{2}+\beta_{3}$ & $\overline{R 2}$ (mean) & $\overline{R 2}$ (median) & & \\
\hline & & $Q 1 A$ & $\begin{array}{l}0.904 \\
(36.63)\end{array}$ & $\begin{array}{l}0.005 \\
(0.29)\end{array}$ & $\begin{array}{l}-0.102 \\
(-4.49)\end{array}$ & $\begin{array}{l}0.808 \\
(21.45)\end{array}$ & 0.099 & 0.080 & \\
\hline & & $Q 1 B$ & $\begin{array}{l}0.924 \\
(28.06)\end{array}$ & $\begin{array}{l}0.028 \\
(1.39)\end{array}$ & $\begin{array}{l}-0.096 \\
(-3.86)\end{array}$ & $\begin{array}{l}0.857 \\
(18.74)\end{array}$ & 0.100 & 0.078 & \\
\hline & & $Q 2 A$ & $\begin{array}{l}0.846 \\
(34.60)\end{array}$ & $\begin{array}{l}-0.002 \\
(-0.12)\end{array}$ & $\begin{array}{l}-0.063 \\
(-3.10)\end{array}$ & $\begin{array}{l}0.781 \\
(21.72)\end{array}$ & 0.085 & 0.075 & \\
\hline & & $Q 2 B$ & $\begin{array}{l}0.912 \\
(24.74)\end{array}$ & $\begin{array}{l}0.053 \\
(2.29)\end{array}$ & $\begin{array}{l}-0.062 \\
(-3.13)\end{array}$ & $\begin{array}{l}0.903 \\
(18.98)\end{array}$ & 0.096 & 0.083 & \\
\hline & & $Q 3 A$ & $\begin{array}{l}0.810 \\
(45.86)\end{array}$ & $\begin{array}{l}-0.004 \\
(-0.28)\end{array}$ & $\begin{array}{l}-0.038 \\
(-2.59)\end{array}$ & $\begin{array}{l}0.768 \\
(28.78)\end{array}$ & 0.099 & 0.099 & \\
\hline & & $Q 3 B$ & $\begin{array}{l}0.840 \\
(38.11)\end{array}$ & $\begin{array}{l}0.022 \\
(1.45)\end{array}$ & $\begin{array}{l}-0.069 \\
(-4.17)\end{array}$ & $\begin{array}{l}0.793 \\
(25.26)\end{array}$ & 0.098 & 0.091 & \\
\hline & & $Q 4 A$ & $\begin{array}{l}0.790 \\
(55.52)\end{array}$ & $\begin{array}{l}-0.013 \\
(-1.24)\end{array}$ & $\begin{array}{l}-0.020 \\
(-1.70)\end{array}$ & $\begin{array}{l}0.756 \\
(35.14)\end{array}$ & 0.120 & 0.117 & \\
\hline & & $Q 4 B$ & $\begin{array}{l}0.789 \\
(45.43)\end{array}$ & $\begin{array}{l}0.007 \\
(0.48)\end{array}$ & $\begin{array}{l}-0.056 \\
(-3.83)\end{array}$ & $\begin{array}{l}0.740 \\
(27.88)\end{array}$ & 0.100 & 0.099 & \\
\hline & & $Q 5 A$ & $\begin{array}{l}0.776 \\
(60.04)\end{array}$ & $\begin{array}{l}-0.015 \\
(-1.63)\end{array}$ & $\begin{array}{l}-0.019 \\
(-1.78)\end{array}$ & $\begin{array}{l}0.742 \\
(38.84)\end{array}$ & 0.139 & 0.148 & \\
\hline & & $Q 5 B$ & $\begin{array}{l}0.773 \\
(45.38)\end{array}$ & $\begin{array}{l}0.008 \\
(0.60)\end{array}$ & $\begin{array}{l}-0.043 \\
(-2.74)\end{array}$ & $\begin{array}{l}0.738 \\
(27.13)\end{array}$ & 0.096 & 0.095 & \\
\hline \multicolumn{10}{|c|}{ PANEL B: Percentage of positive and negative slope coefficients } \\
\hline & $\beta_{1}$ & & & $\beta_{2}$ & & & $\beta_{3}$ & & \\
\hline & $(+)$ & sig. $(+)$ & sig. $(-)$ & $(+)$ & sig. $(+)$ & sig. (-) & $(+)$ & sig. $(+)$ & sig. (-) \\
\hline$Q 1 A$ & $99.25 \%$ & $88.72 \%$ & $0 \%$ & $57.14 \%$ & $2.26 \%$ & $6.77 \%$ & $36.09 \%$ & $5.26 \%$ & $12.78 \%$ \\
\hline$Q 1 B$ & $99.25 \%$ & $85.71 \%$ & $0 \%$ & $56.39 \%$ & $3.76 \%$ & $6.77 \%$ & $39.85 \%$ & $3.01 \%$ & $12.78 \%$ \\
\hline$Q 2 A$ & $99.25 \%$ & $90.23 \%$ & $0 \%$ & $46.62 \%$ & $6.02 \%$ & $6.77 \%$ & $45.11 \%$ & $3.76 \%$ & $12.03 \%$ \\
\hline$Q 2 B$ & $99.25 \%$ & $87.22 \%$ & $0 \%$ & $54.14 \%$ & $8.27 \%$ & $11.28 \%$ & $40.60 \%$ & $4.51 \%$ & $14.29 \%$ \\
\hline$Q 3 A$ & $99.25 \%$ & $95.49 \%$ & $0 \%$ & $42.86 \%$ & $7.52 \%$ & $8.27 \%$ & $37.59 \%$ & $4.51 \%$ & $11.28 \%$ \\
\hline$Q 3 B$ & $99.25 \%$ & $90.98 \%$ & $0 \%$ & $47.37 \%$ & $6.77 \%$ & $4.51 \%$ & $33.83 \%$ & $3.76 \%$ & $14.29 \%$ \\
\hline$Q 4 A$ & $99.25 \%$ & $96.99 \%$ & $0 \%$ & $37.59 \%$ & $5.26 \%$ & $9.77 \%$ & $40.60 \%$ & $5.26 \%$ & $7.52 \%$ \\
\hline$Q 4 B$ & $99.25 \%$ & $91.73 \%$ & $0 \%$ & $51.13 \%$ & $5.26 \%$ & $4.51 \%$ & $733.08 \%$ & $3.76 \%$ & $10.53 \%$ \\
\hline Q5A & $100 \%$ & $96.99 \%$ & $0 \%$ & $45.11 \%$ & $6.77 \%$ & $12.03 \%$ & $42.11 \%$ & $6.02 \%$ & $12.03 \%$ \\
\hline$Q 5 B$ & $99.25 \%$ & $94.74 \%$ & $0 \%$ & $51.88 \%$ & $2.26 \%$ & $3.76 \%$ & $34.59 \%$ & $3.76 \%$ & $10.53 \%$ \\
\hline \multicolumn{10}{|c|}{ PANEL C: Check for cross-equation dependence in estimation error } \\
\hline & & & average corr. & mean $t$-stat & median $t$-stat & $|t|>1.645$ & $|t|>1.96$ & & \\
\hline & & $Q 1 A$ & 0.004 & -0.051 & -0.132 & $7.58 \%$ & $5.30 \%$ & & \\
\hline & & $Q 1 B$ & 0.009 & -0.004 & 0.062 & $7.58 \%$ & $6.06 \%$ & & \\
\hline & & $Q 2 A$ & 0.003 & -0.048 & -0.161 & $7.58 \%$ & $5.30 \%$ & & \\
\hline & & $Q 2 B$ & 0.003 & 0.004 & -0.073 & $8.33 \%$ & $4.55 \%$ & & \\
\hline & & $Q 3 A$ & 0.003 & -0.008 & 0.002 & $5.30 \%$ & $4.55 \%$ & & \\
\hline
\end{tabular}


Table 1 (continued)

PANEL A: Cross-sectional averages of time series slope coefficients are reported with t-statistics below

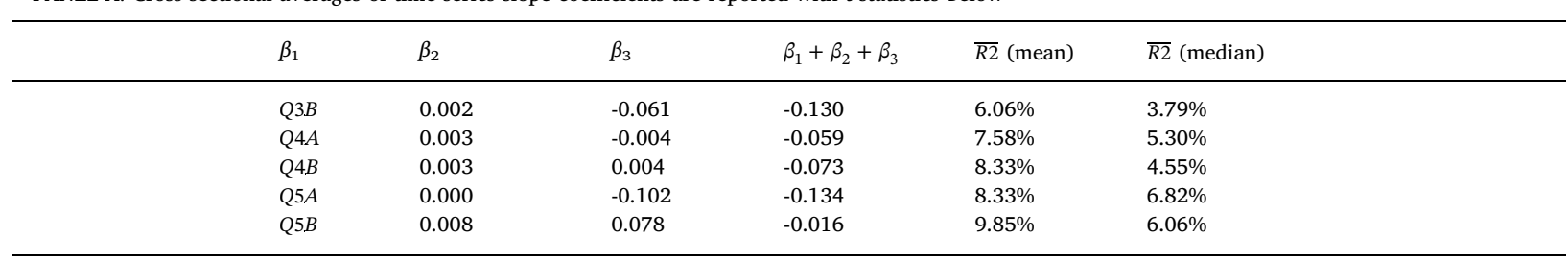

This table presents the market-wide commonality in liquidity using the following multiple regressions:

$D L_{i, t}=\beta_{i 0}+\beta_{i 1} D L_{M, t}+\beta_{i 2} D L_{M, t-1}+\beta_{i 3} D L_{M, t+1}+\beta_{i 4} R_{M, t}+\beta_{i 5} R_{M, t-1}+\beta_{i 6} R_{M, t+1}+\beta_{i 7} D V_{i, t}+\varepsilon_{i, t}$

$Q 1, Q 2, Q 3, Q 4$ and $Q 5$ refer to the amounts of 1000, 10,000, 25000, 50,000 and 100,000 TL respectively, whereas the liquidity measures $A$ and $B$ stand for the cost of ask side and bid side. $D$ preceding the acronym denotes a proportional change in the variable across successive trading days. For each stock, daily percentage changes in liquidity variables for the individual stock $i$, $D L_{i}, t$, are regressed in time series on the percentage change of an equally weighted cross-sectional average of the liquidity variable for all stocks excluding stock $i, D L_{M}, t$, in the sample. Other explanatory variables are the percentage change of the equally weighted cross-sectional average of the return variable for all stocks excluding stock $i$, $R_{M}, t$ in the sample; and daily percentage change in the individual volatility $V_{i, t} \equiv \frac{\left(P_{i, t}^{H}-P_{i, t}^{L}\right)}{\left(P_{i, t}^{H}+P_{i, t}^{L}\right) / 2}$ where $P_{i, t}^{H}$ and $P_{i, t}^{L}$ denote the highest and lowest price of stock $i$ on day $t$ respectively.

Panel A reports the cross-sectional mean of time series slope coefficients with the corresponding $t$-statistics (Only the coefficients of the market liquidity are reported).

In Panel B, $(+)$ reports the proportion of positive coefficients, while sig. $(+)$ and sig. $(-)$ present the percentage which the adjusted $t$-statistics is significantly positive and negative at the $5 \%$ critical level respectively. Panel $\mathrm{C}$ checks for cross-equation dependence:

$\varepsilon_{j+1, t}=\gamma_{j, 0}+\gamma_{j, 1} \varepsilon_{j, t}+\zeta_{j, t} \quad(j=1, \ldots, 132)$,

After estimating 133 time series regressions of individual liquidity measures on equal weighted market liquidity, residuals for stock $j+1$ are compared with residuals for stock $j$, where $j$ is ordered alphabetically. From these 132 pairs, the table reports the average correlation coefficient. Also reported from pair-wise regressions above are the sample mean and median $t$-statistic of the regression slope coefficient and the frequency of absolute $t$ - statistics (for the slope) exceeding typical critical levels, $5 \%$ and $2.5 \%$. Because there are two tails, double these critical percentages (i.e. $10 \%$ and $5 \%$ respectively) should be found just by chance if, in fact, there is no dependence.

information asymmetry in Borsa Istanbul, which is in contrast to the cases of many hybrid or quote-driven markets with specialists (Chordia et al., 2000; Brockman and Chung, 2002; Brockman et al., 2009; Chung and Chuwonganant, 2014). Therefore, liquidity provision strategies of day traders (so called natural market makers) do not necessarily take the industry-specific risk into account for this specific market, even if these traders are risk averse or concern about adverse selection. ${ }^{\text {? }}$

Another interesting result is the negative marginal impact of share price on the cost of trading. A possible explanation for this situation is the fact that prices are not continuous but discrete. Accordingly, all stocks liquid enough to trade at the minimum spread would display a substantial negative correlation between price and proportional spread. This spurious effect would disappear only when price reaches a level high enough to support occasional spreads larger than the minimum (Chordia et al., 2000). This is more than a suitable explanation in our case since the size of the bid-ask spread at best prices stick to one price tick more than $90 \%$ of the time.

As a final notification, we report that after controlling for several factors, the striking switching pattern between commonality on ask- and bid-side is still present. According to Fig. 2, market-wide commonality $\left(\alpha_{1}+\alpha_{2}+\alpha_{3}\right)$ on the bid-side is higher than the askside when we consider the smallest position size Q1. However, as we walk up the order book, although the overall commonality decreases, the commonality on the ask-side gets stronger than the commonality on the bid-side. ${ }^{8}$

\subsection{A potential explanation for the switching pattern}

A possible explanation for the striking switching pattern in commonality may be due to the biased recognition of the trend in the market (Lakonishok et al., 1994; Barberis et al., 1998; Benartzi, 2001). Accordingly, investors over-react to a positive trend in the

\footnotetext{
${ }^{7}$ Although the non-existence of a significant industry-wide commonality is counter-intuitive, it is not uncommon in the literature. For example, Galariotis and Giouvris (2007) find no evidence of industry effect for FTSE250 shares traded on London Stock Exchange, and authors argue that this situation depends on the possible firm-specific noise variation. Similarly, in the case of Australia (another order-driven market), findings of Fabre and Frino (2004) do not support the existence of commonality in liquidity at the industry group level, although authors do not provide any reasoning for this finding. In another study, Kamara et al. (2008) find that the industry betas are much lower relative to the market betas (and insignificant in some cases), which suggests that liquidity commonality is mostly a market-wide effect, not industry specific.

${ }^{8}$ One could notice that the switching in the previous case occurs from size Q3 to Q4, whereas in this case it occurs from size Q1 to Q2. We believe that this is due to regression types we apply. In the previous case, we use returns in the regression whereas we use log-levels in the current one. A quick check shows that if we include lead, lag and concurrent industry liquidity terms in the previous model, then switching occurs from size Q2 to Q3.
} 
I

ம்

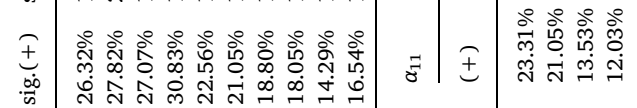

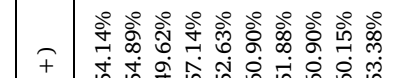

- 它守的

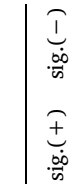

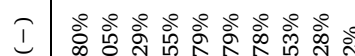

8

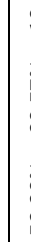

늑 늑 극

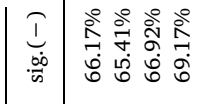

| I

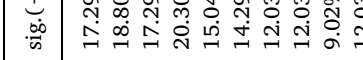

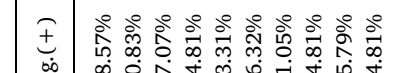

Ғ

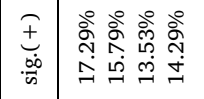

兽

ஸึ่

字全

8

$\mid$

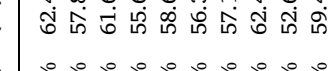

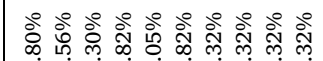

ปั่

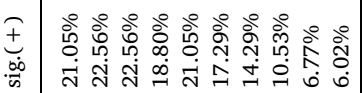

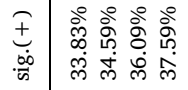

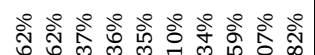

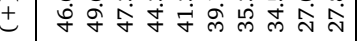

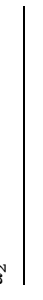

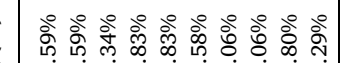

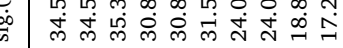

モ

ம்

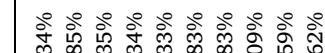

Æ

ป กั่

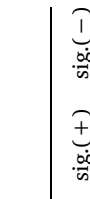

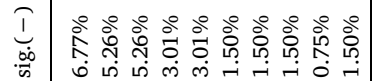

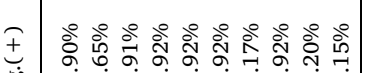

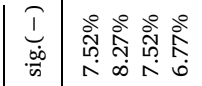

然

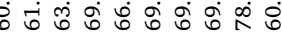

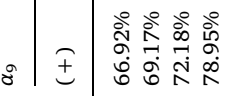

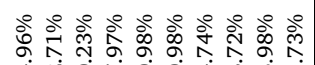
एं

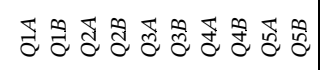




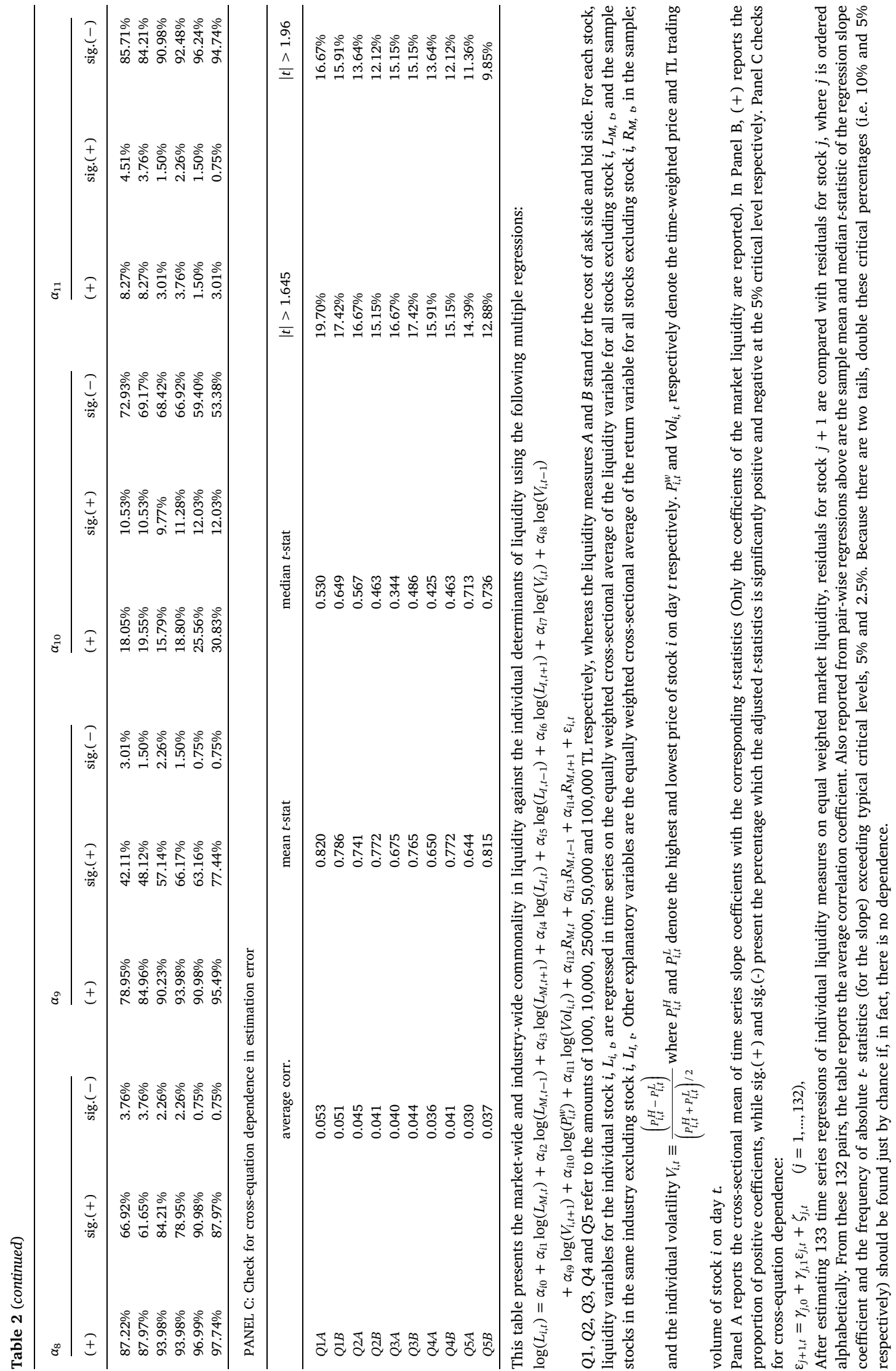




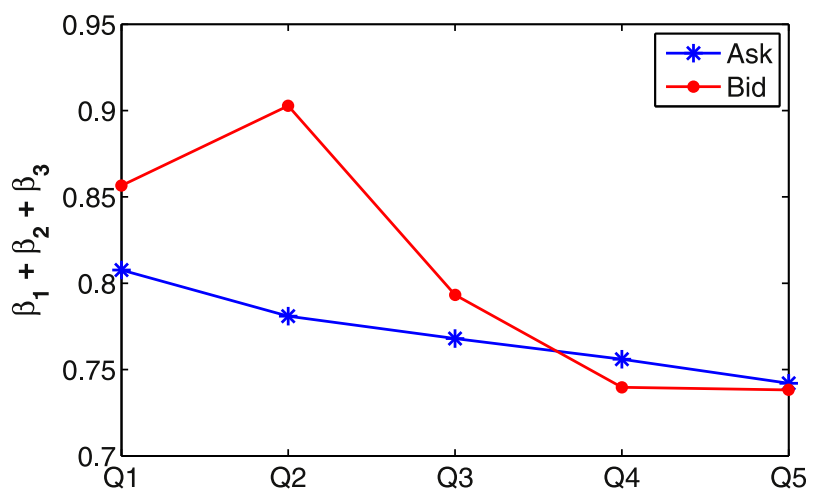

Fig. 1. Sum of the cross-sectional means of concurrent, lagged and lead market liquidity coefficients. Position sizes Q1, Q2, Q3, Q4 and Q5 refer to $1000,10,000,25,000,50,000$ and 100,000 TL respectively.

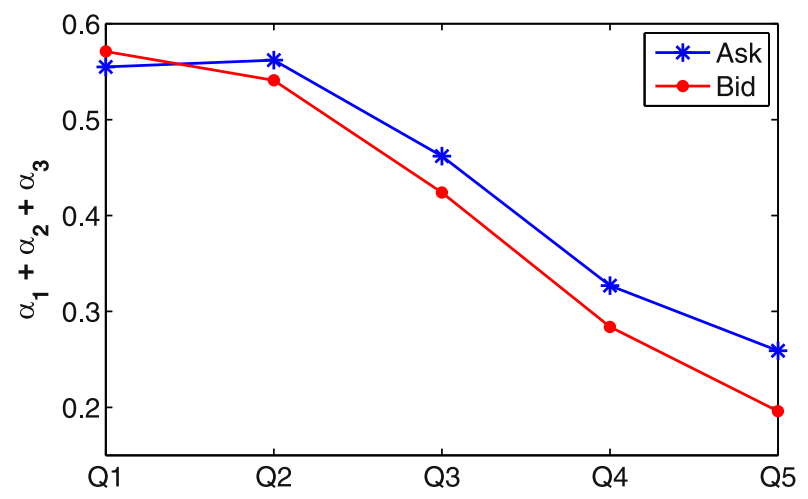

Fig. 2. Sum of the cross-sectional means of concurrent, lagged and lead market liquidity coefficients when the industry affiliation and individual liquidity determinants are taken into account. Position sizes Q1, Q2, Q3, Q4 and Q5 refer to 1000, 10,000, 25,000, 50,000 and 100,000 TL respectively.

market; i.e., over-extrapolate positive past performance into the future by believing that persistence of positive performance to be higher than it actually will, thus even they wish to sell their stocks, they are not willing to do it at a price that is close to the market level; so their sell orders possibly concentrate at higher price in the order book, resulting with a higher commonality for large position sizes to trade on the ask-side. ${ }^{9}$ On the other hand, investors under-react to a negative trend in the market (anticipate this trend to end in a short while), thus set off buy orders with prices closer to the market level (showing that they are willing to pay relatively high prices since they think they will still profit as the market price will change its direction) which may create a higher bid-side commonality for small positions to trade.

To support this argument, we run the following regression:

$$
D L_{M, t}=\beta_{0}+\beta_{1} R_{M, t}^{+}+\beta_{2} R_{M, t}^{-}+\beta_{3} R_{M(5), t}^{+}+\beta_{4} R_{M(5), t}^{-}+\beta_{5} V_{M, t}+\beta_{6} \sigma_{M(5), t}+\varepsilon_{t}
$$

where $D L_{M, t}$ is the daily percentage change of the market liquidity (different from the previous sections, the market liquidity variable in this part is constructed without excluding any of the sample individual stocks), $R_{M, t}^{+}\left(R_{M, t}^{-}\right)$is the daily return of the all share index of Borsa Istanbul when the return is positive (negative) and zero otherwise. $R_{M(5), t}^{+}\left(R_{M(5), t}^{-}\right)$is the past five trading-day all share index return if it is positive (negative) and zero otherwise. Market volatility, denoted by $V$, is defined as $V \equiv \frac{\left(P_{t}^{H}-P_{t}^{L}\right)}{\left(P_{t}^{H}+P_{t}^{L}\right) / 2}$ where $P_{t}^{H}$ and $P_{t}^{L}$ are the highest and lowest values of all share index on day $t$, and $\sigma_{M(5), t}$ is the market standard deviation in the past five trading days. The daily all share index moves could trigger changes in investor expectations while also prompting changes in optimal portfolio compositions. In addition, the direction of the movements could trigger asymmetric effects. Recent market history is also included since many investors use technical analysis strategies in their trading activity. Finally, concurrent and historic volatility is included due to their potential influence on short-term speculative trading. Since OLS runs indicate significant negative serial correlations as displayed in Panel A of Table 3, we apply the Cochrane and Orcutt (1949) iterative correction procedure in the time-series regressions.

\footnotetext{
9 This kind of a behavior is highly related to the "endowment effect" (Thaler, 1980) which prompts an implicitly irrational decision maker to ask a higher price when selling an asset than he would be willing to pay when buying it. A recent study on Australian stock exchange by Fursche and Johnstone (2006) shows that sellers appear to value their own shares higher than buyers independent of current market price, by consistently placing sell orders on average "further from the market" (i.e., from the best quote) than buy orders.
} 
Table 3

\begin{tabular}{|c|c|c|c|c|c|c|}
\hline \multicolumn{7}{|c|}{ PANEL A: Autocorrelations of liquidity variables } \\
\hline & 1st order & 2nd order & 3rd order & 4th order & \multicolumn{2}{|l|}{5 th order } \\
\hline Q1A & -0.289 & -0.011 & 0.001 & -0.020 & \multicolumn{2}{|l|}{0.019} \\
\hline Q1B & -0.316 & 0.000 & -0.007 & -0.034 & \multicolumn{2}{|l|}{0.039} \\
\hline Q2A & -0.249 & -0.013 & -0.039 & -0.015 & \multicolumn{2}{|l|}{0.011} \\
\hline$Q 2 B$ & -0.281 & -0.025 & -0.017 & -0.052 & \multicolumn{2}{|l|}{0.081} \\
\hline Q3A & -0.204 & -0.039 & -0.027 & -0.039 & \multicolumn{2}{|l|}{0.026} \\
\hline Q3B & -0.215 & -0.079 & -0.011 & -0.049 & \multicolumn{2}{|l|}{0.079} \\
\hline Q4A & -0.162 & -0.061 & -0.022 & -0.045 & \multicolumn{2}{|l|}{0.017} \\
\hline$Q 4 B$ & -0.178 & -0.107 & 0.003 & -0.036 & \multicolumn{2}{|l|}{0.045} \\
\hline Q5A & -0.133 & -0.098 & -0.004 & -0.044 & \multicolumn{2}{|l|}{0.004} \\
\hline Q5B & -0.146 & -0.118 & -0.030 & -0.017 & \multicolumn{2}{|l|}{0.034} \\
\hline \multicolumn{7}{|c|}{ PANEL B: Impact of market movements on market-wide ask- and bid-side liquidity } \\
\hline & $\beta_{2}$ & $\beta_{3}$ & $\beta_{4}$ & $\beta_{5}$ & $\beta_{6}$ & $\overline{R 2}$ \\
\hline \multirow[t]{2}{*}{$Q 1 A$} & -1.025 & 0.029 & 0.046 & 0.361 & \multirow{2}{*}{\multicolumn{2}{|c|}{$\begin{array}{l}-0.435 \\
(-4.62)\end{array}$}} \\
\hline & $(-8.39)$ & $(0.15)$ & $(0.25)$ & $(3.12)$ & & \\
\hline \multirow[t]{2}{*}{$Q 1 B$} & -1.149 & 0.064 & 0.018 & 0.368 & \multicolumn{2}{|l|}{-0.446} \\
\hline & $(-8.38)$ & $(0.31)$ & $(0.09)$ & $(2.83)$ & $(-4.24)$ & \\
\hline \multirow[t]{2}{*}{ Q2A } & -2.089 & 0.2 & 0.526 & 0.826 & \multicolumn{2}{|l|}{-0.886} \\
\hline & $(-10.34)$ & $(0.65)$ & (1.63) & $(4.32)$ & $(-5.71)$ & \\
\hline \multirow[t]{2}{*}{$Q 2 B$} & -2.186 & 0.028 & 0.431 & 0.793 & -0.65 & 0.34 \\
\hline & $(-8.88)$ & $(0.07)$ & (1.16) & (3.40) & $(-3.43)$ & \\
\hline \multirow[t]{2}{*}{ Q3A } & -3.354 & 0.336 & 1.232 & 1.478 & \multicolumn{2}{|l|}{-1.35} \\
\hline & $(-11.26)$ & $(0.73)$ & (2.74) & $(5.23)$ & $(-5.88)$ & \\
\hline \multirow[t]{2}{*}{ Q3B } & -3.139 & -0.151 & 1.153 & 1.522 & \multicolumn{2}{|l|}{-1.078} \\
\hline & $(-9.1)$ & $(-0.28)$ & $(2.21)$ & $(4.65)$ & $(-4.04)$ & \\
\hline \multirow[t]{2}{*}{$Q 4 A$} & -4.74 & 0.503 & 1.951 & 2.167 & \multicolumn{2}{|l|}{-1.824} \\
\hline & $(-11.84)$ & $(0.81)$ & (3.21) & (5.70) & $(-5.87)$ & \\
\hline \multirow[t]{2}{*}{ Q4B } & -4.105 & -0.163 & 1.79 & 2.203 & -1.458 & 0.38 \\
\hline & $(-9.28)$ & $(-0.24)$ & $(2.67)$ & (5.24) & $(-4.25)$ & \\
\hline$Q 5 A$ & -6.294 & 0.529 & 2.946 & 2.818 & -2.275 & 0.45 \\
\hline & $(-12.07)$ & $(0.65)$ & (3.7) & (5.67) & $(-5.58)$ & \\
\hline Q5B & -4.853 & -0.134 & 2.76 & 2.725 & -1.642 & 0.40 \\
\hline & $(-9.32)$ & $(-0.17)$ & (3.47) & (5.49) & $(-4.03)$ & \\
\hline
\end{tabular}

Panel A reports the autocorrelation coefficients for the market-wide equally weighted averages of individual liquidity variables. Q1, Q2, Q3, Q4 and Q5 refer to the amounts of $1000,10,000,25,000,50,000$ and 100,000 TL respectively, whereas the liquidity measures $A$ and $B$ stand for the cost of ask-side and bid-side. Numbers in bold font indicate a $p$-value less than 0.0001 for an asymptotic test that the autocorrelation coefficient is zero. Panel B reports the results of the following time-series regressions:

$D L_{M, t}=\beta_{0}+\beta_{1} R_{M, t}^{+}+\beta_{2} R_{M, t}^{-}+\beta_{3} R_{M(5), t}^{+}+\beta_{4} R_{M(5), t}^{-}+\beta_{5} V_{M, t}+\beta_{6} \sigma_{M(5), t}+\varepsilon_{t}$

where the dependent variable $D L_{M, t}$ is the daily percentage change of an equally weighted cross-sectional average of the liquidity variable for all stocks in the sample. $R_{M, t}^{+}\left(R_{M, t}^{-}\right)$is the daily return of the all share index of Borsa Istanbul when the return is positive (negative) and zero otherwise. $R_{M(5), t}^{+}\left(R_{M(5), t}^{-}\right)$is the past five trading-day all share index return if it is positive (negative) and zero otherwise. Market volatility, denoted by $V$, is defined as $V \equiv \frac{\left(P_{t}^{H}-P_{t}^{L}\right)}{\left(P_{t}^{H}+P_{t}^{L}\right) / 2}$ where $P_{t}^{H}$ and $P_{t}^{L}$ are the highest and lowest values of all share index on day $t$, and $\sigma_{M(5), t}$ is the market standard deviation in the past five trading days.

Panel B of Table 3 reports the estimation results.

The results reported in Panel B of Table 3 reveal that a recently falling market $\left(R_{M(5), t}^{-}\right)$tends to be associated with decreased aggregate cost of trading for both sides as the coefficient $\beta_{4}$ of Eq. (3) takes significant positive values. For example, investors on the bid-side become willing to buy a stock at a significantly higher price (closer to the market value) on the average, possibly thinking that they will profit anyway as the stock price will go up. Since the accumulation of buy orders occur close to the market price levels in this case, we observe higher bid-side commonality for small position sizes to trade. On the other hand, a recently rising market $\left(R_{M(5), t}^{+}\right)$has no effect on aggregate liquidity (see $\beta_{3}$ in Table 3). Therefore, when a positive trend occurs in the market, investors on the ask-side are not willing the sell their stocks at prices close to the market level; possibly thinking that they will still profit since the stock price will not change its direction soon. This creates an accumulation of sell orders with prices far from to market level, hence creating higher ask-side commonality for large position sizes to trade.

\section{Conclusion}

As a proxy for liquidity, we use a special weighted spread that measures the cost of buying and selling for a given amount of position, and we look for commonality in liquidity on different sides and also at the different levels of the order book. We find that market-wide commonality in liquidity exists at different levels of the order book for both ask- and bid-side, even after controlling for several factors. Although commonality in cost of trading decreases as the position size to trade increase for both sides, a striking switching pattern arises in this process. Accordingly, bid-side has a higher commonality than ask-side for small position sizes to trade, 
whereas ask-side commonality becomes stronger once position size exceeds a certain level. We empirically support the idea that this switching pattern may be due to the investors' over-reaction to positive market trend and under-reaction to negative market trend.

It is a common assumption that retail investors trade in small sizes, whereas institutional investors' trades are much larger. Our findings imply that retail investors are more prone to the systematic liquidity risk on the bid-side, whereas institutional investors face with a higher systematic liquidity risk on the ask-side. Traders that want to face less systematic transaction costs risk should take market momentum, intended trade direction and the desired order amount to be traded into consideration.

\section{References}

Acharya, V., Pedersen, L.H., 2005. Asset pricing with liquidity risk. J. Financ. Econ. 77, 375-410.

Barberis, N., Shleifer, A., Vishny, R., 1998. A model of investor sentiment. J. Financ. Econ. 49, 307-343.

Bekaert, G., Harvey, C.R., Lundblad, C., 2007. Liquidity and expected returns: lessons from emerging markets. Rev. Financ. Stud. 20, 1783-1831.

Benartzi, S., 2001. Excessive extrapolation and the allocation of 401(k) accounts to company stock. J. Finance 56, $1747-1764$.

Benston, G., Hagerman, R., 1974. Determinants of bid-ask spreads in the over-the-counter market. J. Financ. Econ. 1, 353-364.

Brennan, M.J., Chordia, T., Subrahmanyam, A., Tong, Q., 2012. Sell-order liquidity and the cross-section of expected stock returns. J. Financ. Econ. 105, 523-541. Brockman, P., Chung, D.Y., 2002. Commonality in liquidity: evidence from an order-driven market structure. J. Financ. Res. 25, 521-539.

Brockman, P., Chung, D.Y., Perignon, C., 2009. Commonality in liquidity: a global perspective. J. Financ. Quant. Anal. 44, 851-882.

Chordia, T., Roll, R., Subrahmanyam, A., 2000. Commonality in liquidity. J. Financ. Econ. 56, 3-28.

Chung, K.H., Chuwonganant, C., 2014. Uncertainty, market structure, and liquidity. J Financ. Econ. 113, 476-499.

Cochrane, D., Orcutt, G.H., 1949. Application of least squares regression to relationships containing auto-correlated error terms. J. Am. Stat. Assoc. 44, 32-61.

Domowitz, I., Hansch, O., Wang, X., 2005. Liquidity commonality and return co-movement. J. Financ. Markets 8, 351-376.

Fabre, J., Frino, A., 2004. Commonality in liquidity: evidence from the Australian Stock Exchange. Account. Finance 44, 357-368.

Fursche, A., Johnstone, D., 2006. Evidence of the endowment effect in stock market order placement. J. Behav. Finance 7, 145-154.

Galariotis, E.C., Giouvris, E., 2007. Liquidity commonality in the London Stock Exchange. J. Bus., Finance Account. 34, 374-388.

Hameed, A., Kang, W., Viswanathan, S., 2010. Stock market declines and liquidity. J. Finance 65, 257-293.

Hasbrouck, J., Seppi, D.J., 2001. Common factors in prices, order flows, and liquidity. J. Financ. Econ. 59, $383-411$.

Huberman, G., Halka, D., 2001. Systematic liquidity. J. Financ. Res. 24, 161-178.

Kamara, A., Lou, X., Sadka, R., 2008. The divergence of liquidity commonality in the cross-section of stocks. J. Financ. Econ. 89, 444-466.

Korajczyk, R.A., Sadka, R., 2008. Pricing the commonality across alternative measures of liquidity. J. Financ. Econ. 87, 45-72.

Lakonishok, J., Shleifer, A., Vishny, R., 1994. Contrarian investment, extrapolation, and risk. J. Finance 49, 1541-1578.

Pastor, L., Stambaugh, R., 2003. Liquidity risk and expected stock returns. J. Polit. Econ. 113, 642-685.

Rosch, C.G., Kaserer, C., 2014. Market liquidity in the financial crisis: the role of liquidity commonality and flight-to-quality. J. Banking Finance 45, 152-170.

Sadka, R., 2006. Momentum and post-earnings announcement drift anomalies: the role of liquidity risk. J. Financ. Econ. 80, 309-349.

Sensoy, A., 2016. Commonality in liquidity: effects of monetary policy and macroeconomic announcements. Finance Res. Lett. 16, 125-131.

Sensoy, A., 2017. Firm size, ownership structure, and systematic liquidity risk: the case of an emerging market. J. Financ. Stab. 31, 62-80.

Stoll, H., 1978. The pricing of security dealer services: an empirical study of NASDAQ stocks. J. Finance 33, 1153-1172.

Stoll, H., 2000. Friction. J. Finance 55, 1479-1514.

Thaler, R.H., 1980. Towards a theory of consumer choice. J. Econ. Behav. Organiz. 1, 39-60. 